\title{
O quadro tecnogênico das inundações do rio Baquirivu-guaçu, Arujá e Guarulhos, SP
}

\section{The technogenic framework of floods in Baquirivu-guaçu river, Arujá and Guarulhos, SP}

\author{
Daniel Carlos de Campos ${ }^{\text {ab }}$, Antonio Manoel dos Santos Oliveira ${ }^{\text {ac }}$ \\ ${ }^{\mathrm{a}}$ Universidade Guarulhos \\ bacdccampos@hotmail.com, caoliveira@prof.ung.br
}

\begin{abstract}
RESUMO
Embora as inundações sejam fenômenos naturais condicionados por diversos fatores do meio físico, nas áreas urbanas, o homem, por meio de suas atividades econômicas, transforma estes eventos em problemas. Nesse contexto, as experiências ao longo do século XX na Bacia do Alto Tietê - BAT constituem importante referencial para a análise das inundações na bacia do rio Baquirivu-Guaçu, como experiência a ser considerada na seleção de medidas a serem tomadas para o controle desse fenômeno.
\end{abstract}

Palavras-chave: Inundação; Tecnogênico; Rio Baquirivu-Guaçu; Bacia Hidrográfica do Alto Tietê; Guarulhos.

\begin{abstract}
Although floods are natural phenomena, conditioned by various factors of the physical environment, in urban areas, Man, through his economic activities, transforms these events into important matters. In this context, the experience accumulated over the twentieth century in Alto Tietê watershed is an important reference for the analysis of inundation in the Baquirivu-Guaçu watershed, as an experience to be considered in the selection of measures to be taken for flood control.
\end{abstract}

Keywords: Floods; Technogenic; Baquirivu-Guaçu River; Alto Tietê Watershed; Guarulhos.

\section{Introdução}

A bacia do rio Baquirivu-Guaçu, com 165,5 km², sofreu um processo de urbanização tardio em relação à Região Metropolitana de São Paulo (RMSP), a partir da década de 1970, especialmente relacionado à construção do Aeroporto Internacional de São Paulo/Guarulhos (AISP), implantado na várzea do seu rio principal (Baquirivu-Guaçu), margem esquerda, ocasionando modificações na geomorfologia fluvial que, em conjunto com a indução à urbanização que se seguiu, alterou o regime das inundações. Entretanto, os remanescentes de vegetação e várzeas desta bacia indicam a necessidade da adoção de medidas preventivas de controle dessas inundações, tendo como referencial as intervenções nos principais rios da Bacia do Alto Tietê (BAT).

\section{Materiais e métodos}

Para a elaboração do presente artigo, com vistas aos objetivos pretendidos, foi adotada uma abordagem sistêmica, considerando-se a bacia hidrográfica como unidade de estudo, a análise do meio físico - quadro natural - e as alterações do meio físico, decorrentes da urbanização, com destaque para as inundações e suas consequências - quadro tecnogênico.

Foi realizada uma revisão histórica da ocupação urbana na bacia do rio Baquirivu-Guaçu, numa perspectiva de impactos no sistema de drenagem, considerando o processo de urbanização tardio, por meio de levantamento de bibliografia especializada, acervos de teses e dissertações, trabalhos científicos, além de relatórios técnicos elaborados pelo poder público local. O histórico das inundações foi avaliado a partir de arquivos de jornais locais, desde a década de 1960.

Tendo em vista a importância do Aeroporto Internacional de São Paulo/Guarulhos, implantado na bacia do rio Baquirivu-Guaçu, foi considerado o Estudo de Impacto Ambiental (EIA), Infraero (2002), do empreendimento, além dos demais relatórios e estudos a ele relacionados, elaborados durante o processo de licenciamento ambiental do empreendimento.

\section{3. Área objeto}

A bacia do Baquirivu-Guaçu está situada a nordeste da bacia do Alto Tietê (BAT), nos municípios de Guarulhos e Arujá, na margem direita do rio Tietê (figura 1). 


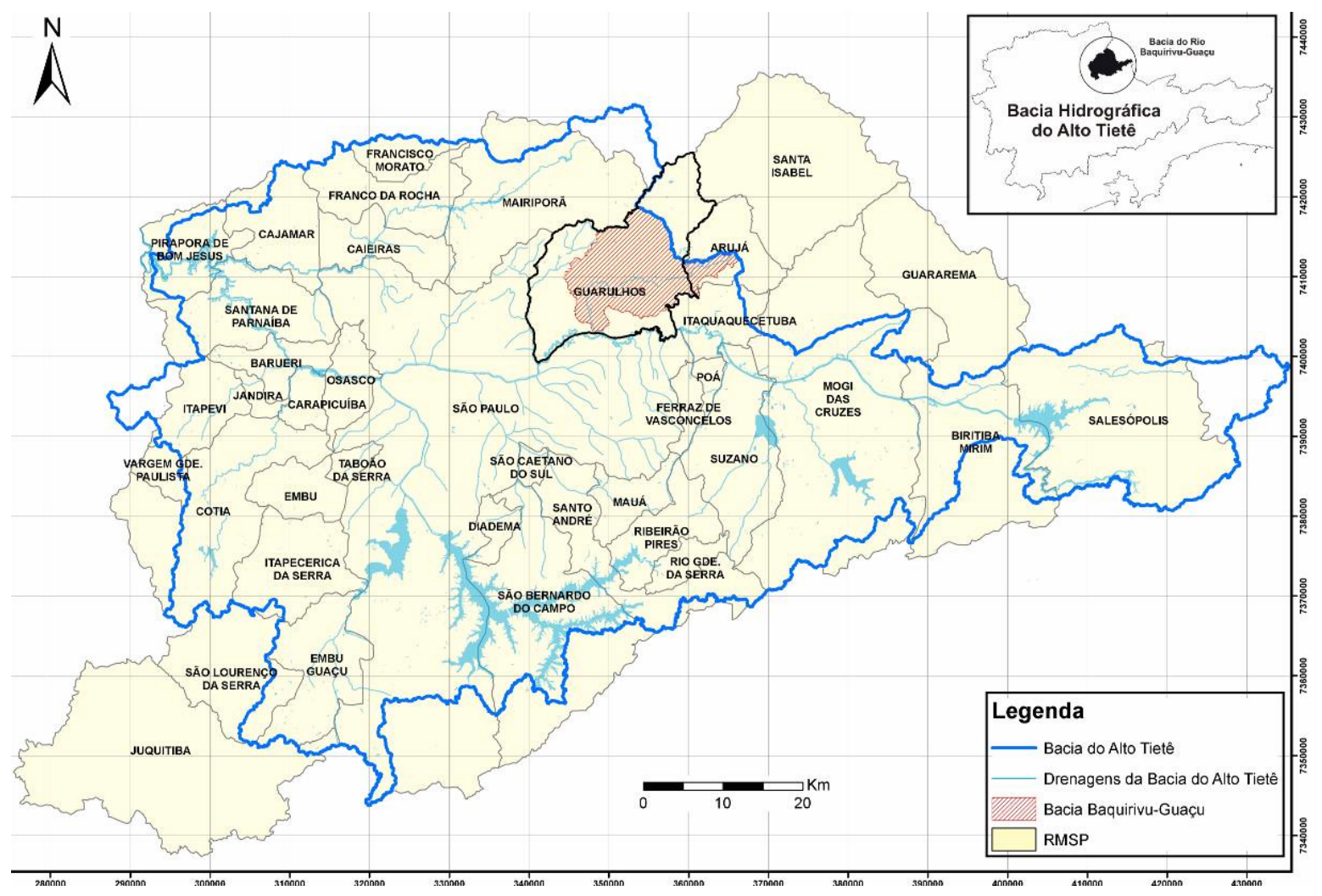

Figura 1: Bacia do Alto Tietê e bacia do rio Baquirivu-Guaçu. Fonte: modificado de Emplasa (2002)

Na RMSP, em relação ao sistema Tietê-Pinheiros, a bacia do rio Baquirivu-Guaçu, com 165,5 km², é superior à do rio Aricanduva $\left(100 \mathrm{~km}^{2}\right)$ e à do Pirajussara $\left(72 \mathrm{~km}^{2}\right)$, sendo inferior somente à bacia do rio Tamanduateí - $320 \mathrm{~km}^{2}$. Em Guarulhos, corresponde a 145,6 km² e em Arujá, a 19,9 km², onde estão suas nascentes.

\section{Objetivo}

O objetivo do presente trabalho é analisar as inundações e seus condicionantes na bacia do rio Baquirivu-Guaçu, tendo em vista que, no atual quadro tecnogênico, o comportamento fluvial deixou de ser natural em decorrência das intervenções que se seguiram: a reprodução do modelo tradicional de "livre” ocupação e medidas corretivas sucessivas.

\section{Condicionantes naturais das inundações}

Entre as diversas conceituações (e.g. Jorge \& Uehara 1998, Riccomini et al. 2000, Mattes 2001, Tucci 2006), no presente trabalho, consideram-se inundações, cheias e enchentes como processos naturais de extravasamento das águas, quando em caso de precipitações intensas, para as áreas marginais dos cursos d’água, ou seja, suas planícies de inundação, várzeas ou leito maior, sendo parte integrante do ciclo hidrológico. As inundações, em situação natural, estão condicionadas principalmente pela intensidade, frequência e duração das chuvas e sua distribuição na bacia hidrográfica, pelas declividades das vertentes e do talvegue principal, definindo os espaços de acomodação (várzeas) das águas que excedem o canal.
A vegetação participa de modo ponderável no comportamento das inundações, tendo em vista seu papel no balanço hídrico das bacias. Segundo Karmann (2000), áreas florestadas de clima quente e úmido devolvem à atmosfera cerca de $70 \%$ da precipitação. Laçava et al. (2009) realizaram estudos na região da Cantareira e encontraram valores semelhantes. O processo de evapotranspiração, exercido pela vegetação, assegura os altos teores de umidade encontrados nas florestas que, assim, cumprem importante papel regulador da temperatura do ar e das chuvas. Cerca de $30 \%$ é retardado pela vegetação e escoa pelas vertentes de modo lento e gradual, ou se infiltra no solo, até chegar aos cursos d’água. A vegetação promove também a proteção contra 0 impacto direto da chuva no solo, controlando os processos erosivos. Enfim, a cobertura vegetal realiza um serviço ecossistêmico importante para o bem-estar humano (Alcamo et al. 2003).

\section{Condicionantes antrópicos das inundações}

O processo de urbanização das bacias da RMSP iniciou-se, predominantemente, pela abertura de lotes nas vertentes, em terrenos com relevo mais suave, como as colinas, e distantes das áreas inundáveis. Neste cenário, a ocupação urbana e as alterações dos processos geohidrológicos, de modo geral, seguiram a seguinte sequência: 1 . Supressão da cobertura vegetal, com diminuição do processo de evapotranspiração e aumento do escoamento superficial; 2. Erosão e assoreamento intensificados (decorrente da supressão da vegetação), carreando os sedimentos pelas vertentes 
até os cursos d’água, diminuindo sua capacidade hidráulica; 3. Impermeabilização do solo, segundo Tucci (2006), que provoca o aumento em até sete vezes do escoamento superficial em relação às condições naturais; 4. Canalizações e retificações, com aumento da condutividade hidráulica dos cursos d’água, elevando as vazões à jusante; 5. Ocupação das várzeas, mediante seu aterramento, confinando as águas e transferindo-as para jusante com mais intensidade; 6 . Implantação de condutos e travessias mal dimensionadas, criando pontos de inundações localizados; e 7. Obstrução da drenagem por resíduos sólidos, gerados pelos processos erosivos nas vertentes, pela construção civil e os produzidos industrialmente. Apesar da ideia muito disseminada de que o lixo é o principal condicionante das inundações, ele ocorre em pequena quantidade nos espaços das calhas dos principais rios. Realizando estudos na calha do rio Tietê, Santos (2002) afirma:

O lixo urbano, ainda que se destaque no aspecto visual, representa apenas 5\% do volume total de material de assoreamento, ou seja, 95\% deste volume corresponde a sedimentos finos provenientes dos processos erosivos e material areno-pedregoso originado da construção civil (Santos 2002).

\section{Bacia do Rio Baquirivu-Guaçu}

Para melhor compreensão do quadro tecnogênico da bacia do rio Baquirivu-Guaçu, será apresentado, primeiramente, um panorama dos aspectos naturais e, posteriormente, as intervenções humanas, desde o período colonial.

\subsection{Aspectos naturais}

O talvegue do rio principal possui declividade geral de 2,24 m/km, com $25 \mathrm{~km}$ de extensão. Suas margens apresentam forte assimetria quanto às características geoambientais. A vertente norte, margem direita, é composta em sua maior parte por rochas cristalinas, solos rasos, terrenos com altitudes acima de $1.000 \mathrm{~m}$ (montanhas e morros) e altas declividades e, em menor proporção, por sedimentos da Bacia Sedimentar de São Paulo. Na margem esquerda, ao sul, ocorre o inverso: predominam estes sedimentos, baixas declividades (morrotes e planícies) em altitudes máximas de 820m. As feições da vertente norte geraram uma rica rede de drenagem, com um padrão de drenagem dendrítico, canais encaixados, tendência à concentração, e altas energias de escoamento até a Bacia Sedimentar, onde passa a ter um padrão de drenagem subparalelo, com vales mais amplos e menor energia de escoamento vertente sul. Segundo Campos (2011), a área da margem direita da bacia possui 105,6 km² e a esquerda, $59,9 \mathrm{~km}^{2}$; a densidade de drenagem, na margem direita, corresponde a $2,32 \mathrm{~km} / \mathrm{km}^{2}$ e a esquerda, $0,92 \mathrm{~km} / \mathrm{km}^{2}$. $\mathrm{O}$ autor identificou também que alguns afluentes da margem direita possuem declividades médias acima de $10 \%$, e na margem esquerda não passam de $4 \%$. A figura 2 apresenta Guarulhos, a bacia do rio BaquirivuGuaçu e a rede de drenagem.

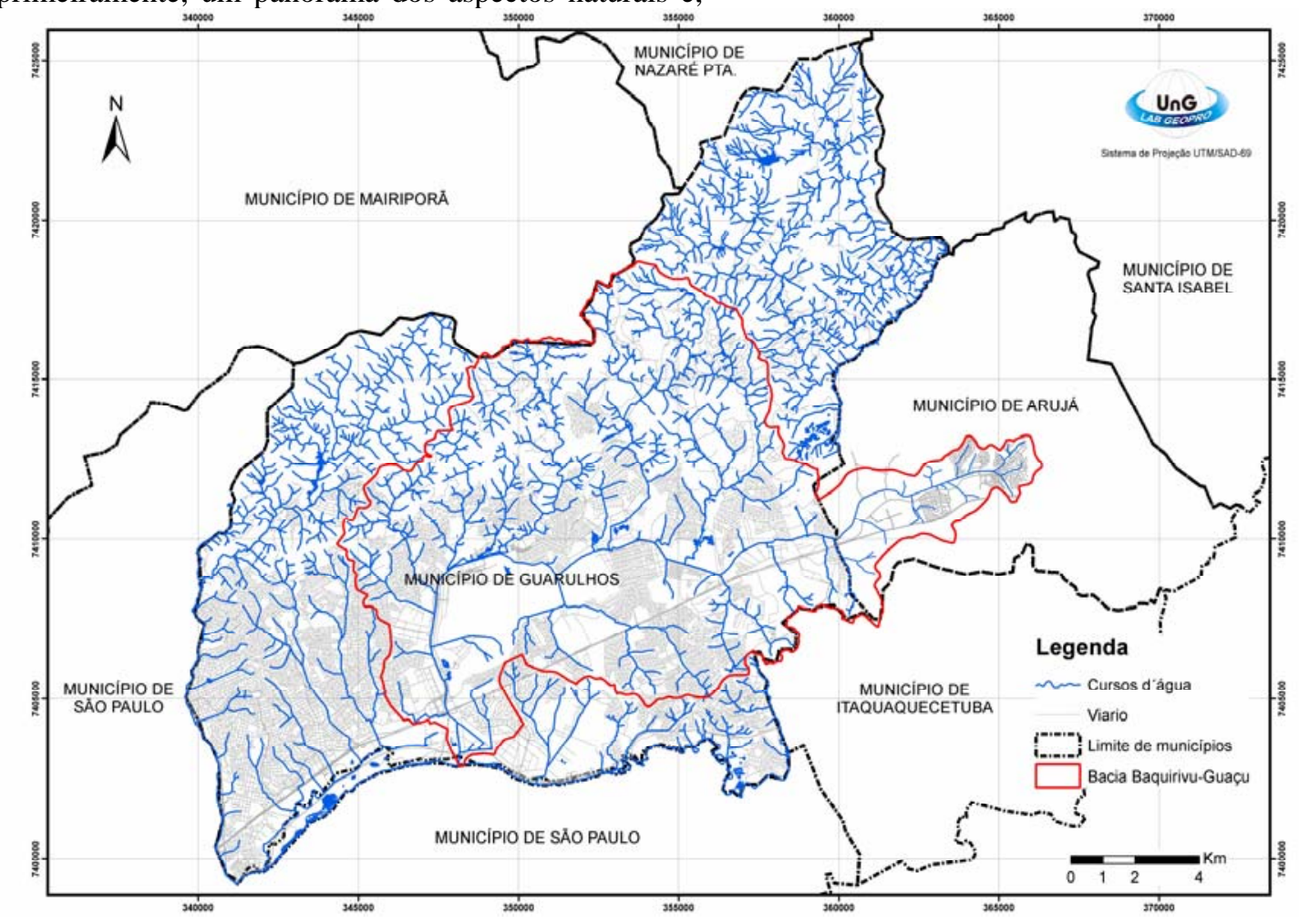

Figura 2: Rede de drenagem da bacia do Baquirivu-Guaçu (Campos 2011) 


\subsection{Aspectos tecnogênicos}

Os aspectos tecnogênicos correspondem às intervenções antrópicas no meio físico e seus efeitos, considerando-se o homem como agente geológico (Oliveira et al. 2005).

As primeiras atividades econômicas e ocupações na bacia do rio Baquirivu-Guaçu que se tem registro remontam ao período colonial. Em 1597, Afonso Sardinha, o velho, descobriu ouro na Serra do Jaguamimbaba, atual Bairro do Morro Grande, também conhecida por Pico do Gil ou do Itaberaba, conjunto de elevações que separam as drenagens do Alto Tietê (Baquirivu-Guaçu) das do Paraíba do Sul e do Piracicaba, Capivari e Jundiaí.

O historiador Manuel Eufrásio de Azevedo Marques, na Nobiliarquia das principais famílias da Capitania de S. Vicente, transcrevendo Pedro Taques e citado por Luís (2004), relata, a respeito de Afonso Sardinha:
Foi o primeiro descobridor das minas de ouro, prata, ferro e aço [sic] em todo o Brasil pelos anos de 1589 nas serras seguintes: na de Jaguamimbaba, que ao presente tempo se conhece com o nome de Mantiqueira; no sítio que agora se diz Lagoas Velhas do Geraldo, distrito da freguesia da Conceição dos Guarulhos, termo da cidade de S. Paulo; na de Jaraguá, onde fez o seu estabelecimento minerando, e aí faleceu (Luís 2004).

Sem dúvida, a atividade aurífera nessa região antecede a de Minas Gerais em mais de 100 anos. A exploração de ouro em Guarulhos e na bacia do rio Baquirivu-Guaçu estendeu-se até aproximadamente 1812, sendo responsável pela consolidação das primeiras estruturas urbanas e pela escravização indígena e de negros, deixando registros tecnogênicos ainda presentes, como exemplo, canais de rocha (figura 3) e escoramento de taludes nas localidades mencionadas.

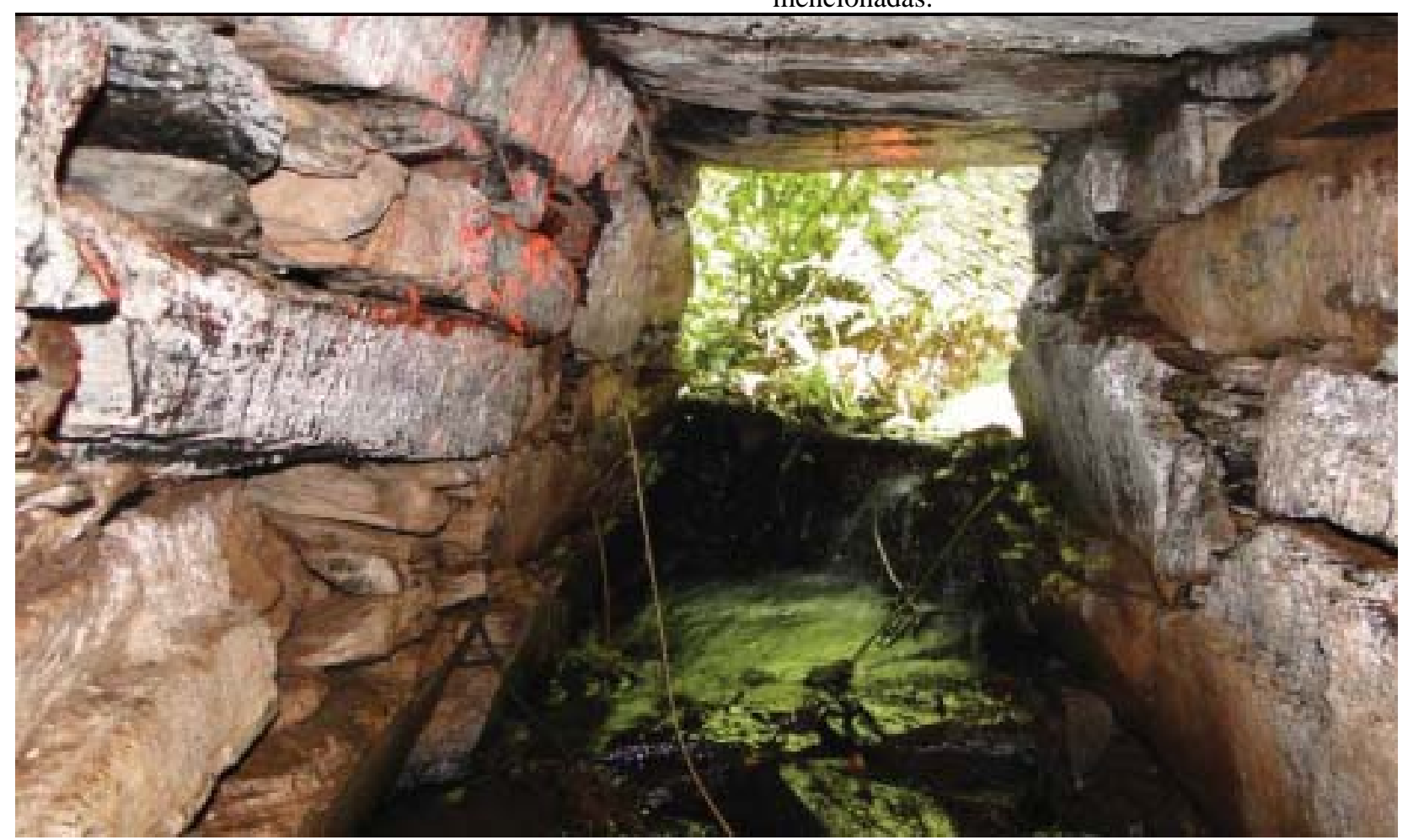

Figura 3:- Duto de pedra de 96m de comprimento usado para o encaminhamento de água para a mineração aurífera. Fonte: Acervo próprio.

Do final do século XIX até a primeira metade do XX iniciou-se outra fase econômica em Guarulhos, qual seja, a da produção de tijolos cozidos para abastecer o mercado da construção civil no município e na capital. Esta técnica foi trazida pelos imigrantes italianos, sendo intensamente desenvolvida. Entretanto, não incentivou a ocupação urbana de maneira significativa. No levantamento aerofotogramétrico, executado pela VASP em 1971, foram identificadas 107 olarias na bacia do Baquirivu-Guaçu e uma ocupação pouco expressiva.

A partir da década de 1970, começou um processo mais intenso de intervenções tecnogênicas na bacia.
Em 1976, havia apenas duas vias pavimentadas em toda a bacia, além da existência de estradas rurais e caminhos, e uma população total de 81.696 habitantes, concentrando-se nas proximidades da rodovia Presidente Dutra, segundo a Emplasa (1976). Entre os anos de 1975 e 1976, foram eliminados pequenos meandros no trecho médio-inferior do rio BaquirivuGuaçu, entre a foz do córrego Cocho Velho e a rodovia Presidente Dutra (figura 4), obra executada pelo Departamento de Águas e Energia do governo estadual, com apoio da prefeitura de Guarulhos (DAEE 1975). 


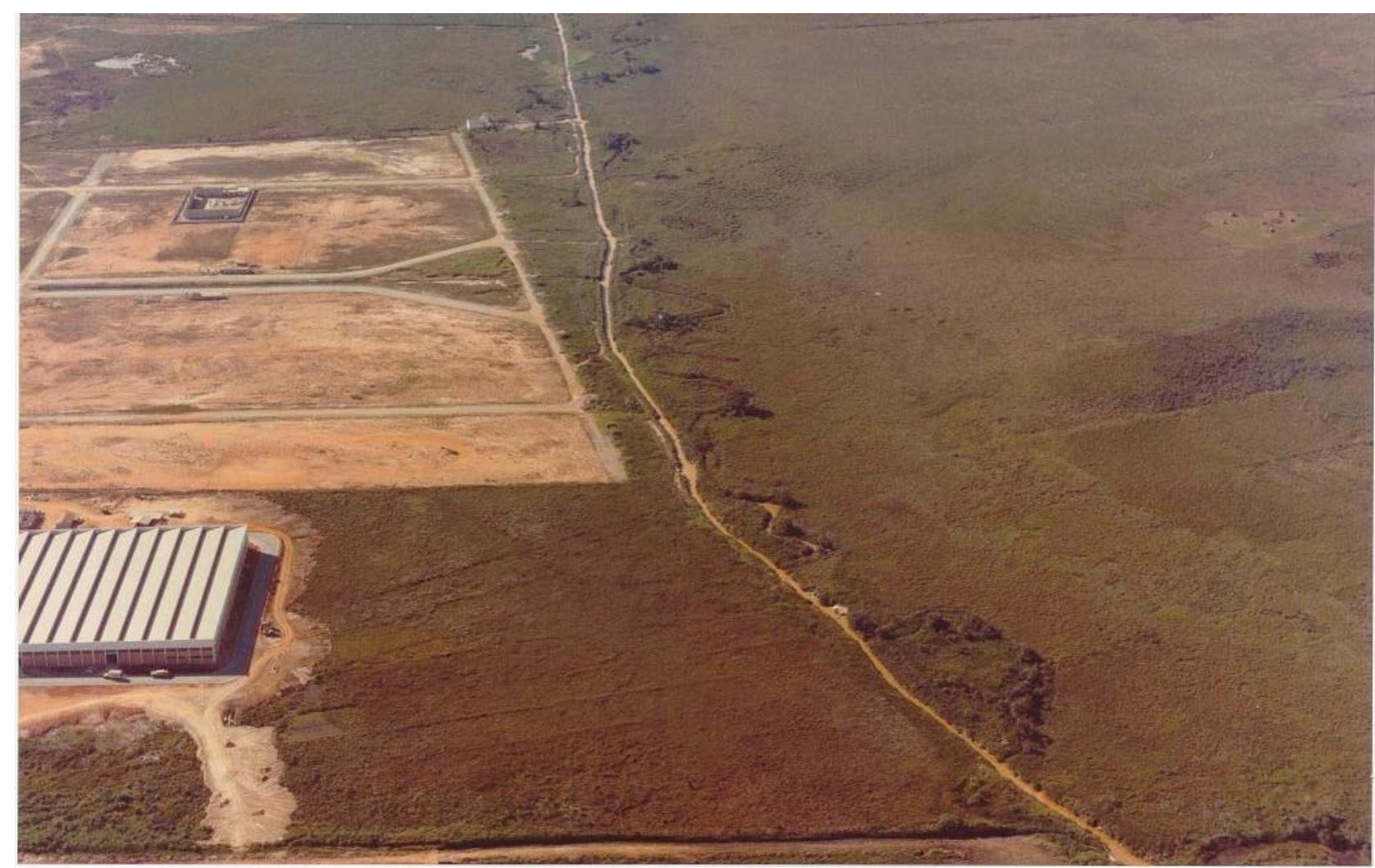

Figura 4: Foto panorâmica do trecho médio do rio Baquirivu-Guaçu, onde podem ser observados seus meandros e o canal construído. Fonte: Infraero (1979)

No final da década de 1970 inicia-se o processo de desapropriação para a construção do aeroporto. Implantado entre 1979 e 1985, no trecho médio do curso do rio Baquirivu-Guaçu, o aeroporto possui área de $14 \mathrm{~km}^{2}$, e sua obra promoveu alterações profundas no sistema fluvial, embora não reconhecidas em seu Estudo de Impacto Ambiental (Infraero 2002), como: retificação e canalização do canal, supressão de várzeas e impermeabilização do solo.

\subsubsection{Retificação e canalização}

Obras de retificação e canalização foram realizadas no curso médio, assim como nos córregos Cocho Velho e Baquirivu-Mirim, afluentes da margem esquerda do rio Baquirivu-Guaçu.

De acordo com DAEE (2002), a alteração da conformação meandrante original do rio BaquirivuGuaçu por um canal de concreto, com maior velocidade de escoamento, reduziu em aproximadamente $2 \mathrm{~km}$ o seu curso, abreviando o tempo de concentração da bacia hidrográfica em cerca de 7\%. As canalizações e retificações dos córregos Baquirivu-Mirim e Cocho Velho desviaram os cursos originais, produzindo novas conformações geométricas (figura 5).

\subsubsection{Supressão da várzea}

Foram realizadas obras de aterro, suprimindo várzeas, eliminando brejos, lagos e terrenos inundáveis, que exerciam a função de amortecimento das águas desta bacia hidrográfica nos períodos de cheias. Fotos aéreas mais antigas e estudos já realizados na região mostram que o terreno ocupado pelo aeroporto, em suas condições naturais, era constituído por uma extensa planície aluvial com declividade em média inferior a $0,2 \%$, contendo diversas lagoas, zonas alagadiças e terrenos mal drenados. Esta área representa a porção mais larga da planície do rio Baquirivu-Guaçu, e o terreno original tornava-se sujeito a inundações frequentes. Parcela significativa das águas fluviais que chegavam à planície aluvial ficava armazenada nos terrenos mais baixos durante o período das cheias, fluindo lentamente em direção ao rio Baquirivu-Guaçu. Essas modificações, mediante o aterramento dos terrenos, promoveram uma profunda alteração nas condições de acomodação das águas.

\subsubsection{Impermeabilização da área do AISP}

A impermeabilização da área do aeroporto envolveu, fundamentalmente, a contribuição das águas pluviais captadas na atual superfície da área do aeroporto que se dirigem ao Baquirivu-Guaçu. A execução do aterro na planície, além de eliminar uma porção significativa da várzea, tornou os terrenos muito menos permeáveis, contribuindo para o aumento das vazões do referido rio. 


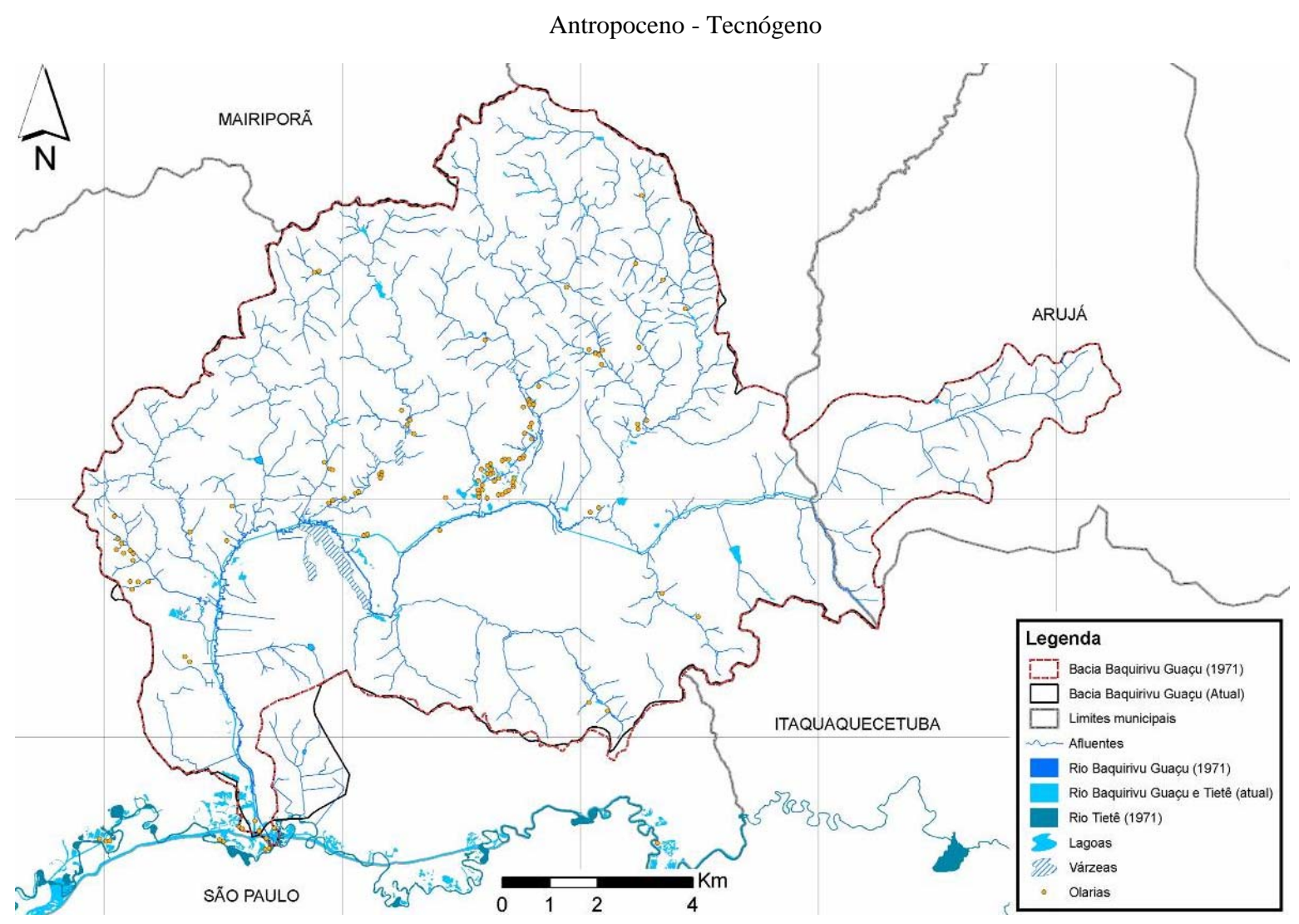

Figura 5: Rio Baquirivu-Guaçu antes e depois das obras do AISP (Campos 2011)

Além desses impactos, o aeroporto intensificou, antes, durante e depois de sua construção, um processo de ocupação urbana em seu entorno, decorrente do potencial de emprego e renda prometido pelo empreendimento e amplamente noticiado pelos periódicos locais e regionais.

Nunca, no mercado imobiliário guarulhense, se aguardou com tanta expectativa por uma valorização. [...] Calcula-se, por exemplo, que mais de 30 mil pessoas vão [sic] circular diariamente dentro do aeroporto. Desses, $90 \mathrm{mil}$ são funcionários do aeroporto e das empresas aéreas e $40 \%$ dessa força de trabalho está sendo contratada junto à população guarulhense [...]. Um Bom Negócio, (Metrô News 1984).

A ocupação foi condicionada, também, pelo fato de essas áreas ocupadas, as várzeas do rio BaquirivuGuaçu, serem de menor valor de mercado, justamente por estarem degradadas ambientalmente, apresentando também condições sanitárias insatisfatórias, atraindo, por essa razão, famílias carentes. A figura 6 apresenta a evolução urbana na bacia do Baquirivu-Guaçu.

\subsection{Inundações}

À medida que a bacia do rio Baquirivu-Guaçu se urbanizava, a percepção das comunidades era de que aumentava a frequência e intensidade das inundações registradas por periódicos da época. Entretanto, não foi possível estabelecer uma relação direta entre as obras realizadas e as inundações. Isto porque se trata de um fenômeno natural que passa a ser problema à medida que estruturas urbanas ocupam os espaços naturais das águas. Ademais, não há registros quantitativos conhecidos da frequência e intensidade das inundações antes de 1970 nesta bacia.

Por conseguinte, as obras do aeroporto estabeleceram efeitos contrários de funcionamento da várzea do Baquirivu. No quadro tecnogênico gerado, as águas perderam seus espaços de transbordamento e acomodação das cheias, e o canal principal foi condicionado ao aumento do escoamento. Se um efeito compensou o outro, o funcionamento da várzea foi profundamente alterado, ficando limitada em sua função de amortecer inundações. As alterações são consistentes com o modelo de ocupação do Alto Tietê, em que a intervenção antrópica subtrai do quadro natural o funcionamento da várzea para ocupar os terrenos.

Como a expansão urbana prossegue, incentivada pela ocupação de novos espaços, o escoamento rápido da água, pelas obras de canalização e retificação, não é suficiente para evitar as novas inundações, agora alteradas pelo novo quadro tecnogênico.

A figura 7 evidencia as áreas de inundações frequentes na bacia. 


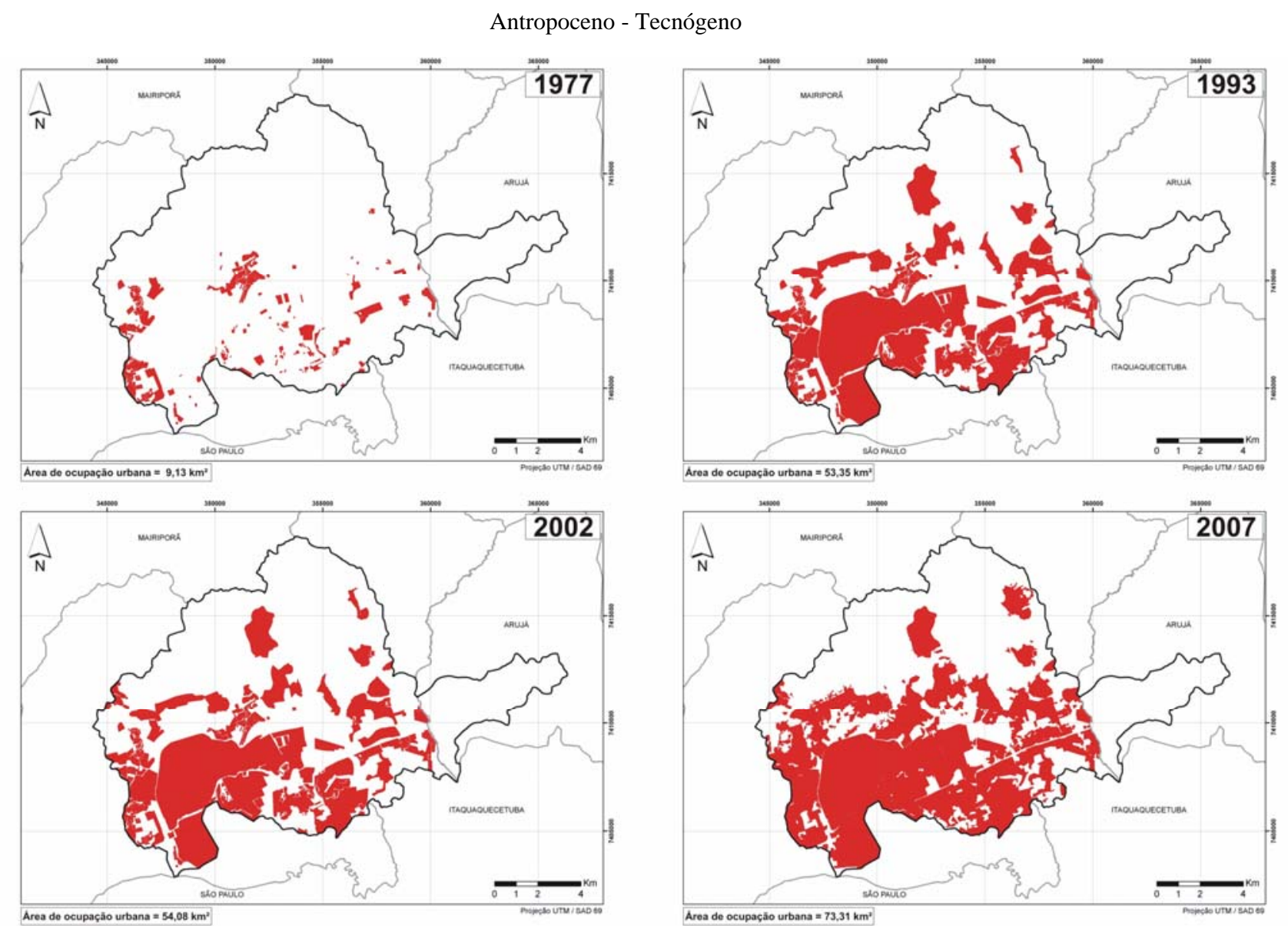

Figura 6: Evolução da área urbana na bacia do rio Baquirivu-Guaçu, segundo Campos (2011)

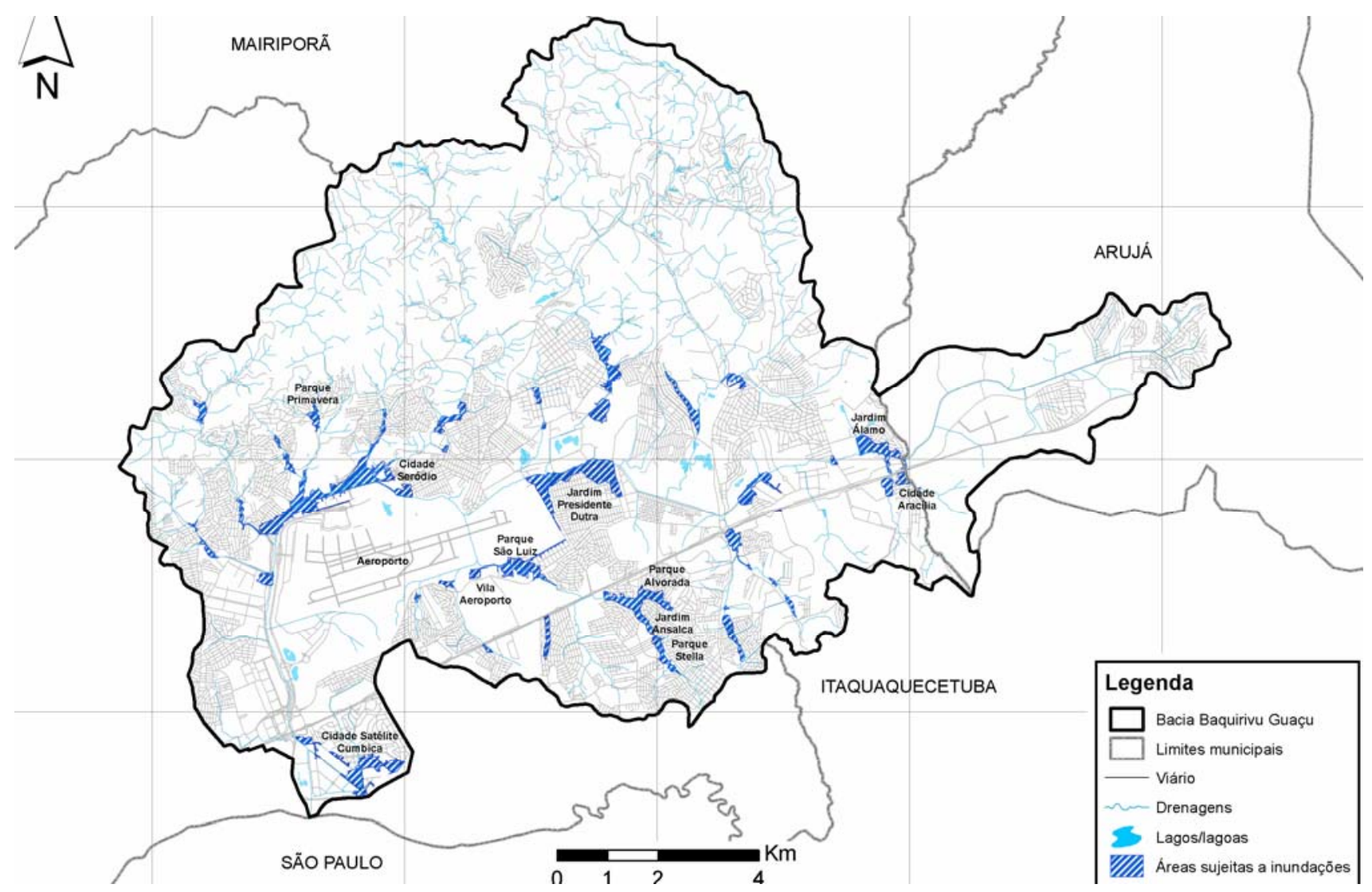

Figura 7: Mapa de inundações frequentes (Guarulhos 2008) 


\section{Antropoceno - Tecnógeno}

Após a eliminação de pequenos meandros do rio Baquirivu-Guaçu, entre 1975 e 1976, realizada pelo DAEE com o apoio da prefeitura de Guarulhos, aumentaram as ocorrências de inundações atingindo áreas urbanas, conforme o jornal O Repórter de Guarulhos, de 2 de fevereiro de 1977:

No dia $1^{\circ}$ de fevereiro [1977], perto de cem pessoas ficaram desabrigadas e as aproximadamente 60 famílias [...] sofreram enormes prejuízos com a água que invadiu suas casas, numa repentina inundação do Baquirivu provocada pela [sua] retificação (Repórter de Guarulhos 1977).

No córrego Cocho Velho, afluente da margem esquerda, segundo Eduardo F. dos Santos, da Defesa Civil (relato verbal em 19 nov. 2010), a frequência das inundações que interditam a rodovia Presidente Dutra é de dois anos e, ainda, segundo o eng. Francisco Acosta Filho, da prefeitura de Guarulhos (relato verbal em 19 nov. 2010), nos dias 7 e 14 de fevereiro de 1999, as inundações interditaram o aeroporto, pois as águas do córrego Cocho Velho, que atravessam também o sítio aeroportuário, invadiram as pistas de pouso e decolagem.

É importante destacar que na vertente norte, menos favorável à ocupação urbana, encontram-se ainda os últimos remanescentes de Mata Atlântica, que representam cerca de 51,8\% da área da bacia, conforme Campos (2011). Isto significa que a supressão desses remanescentes de vegetação potencializará as inundações na planície do rio Baquirivu-Guaçu, atingindo as comunidades residentes no local e comprometendo as operações do aeroporto. Ressalte-se que as obras do Rodoanel "Mario Covas", que atravessa a porção norte da bacia objeto de estudo, estão aceleradas e têm potencial para a indução da ocupação em médio e longo prazo.

Ademais, o aumento da frequência e intensidade das chuvas, constatado na RMSP pelo efeito da ilha de calor (Pereira Filho et al. 2007), que pode ainda ser intensificado pelas mudanças climáticas prognosticadas para o Sudeste brasileiro, e a perspectiva de expansão urbana na vertente direita do rio Baquirivu-Guaçu, onde ainda subsistem vastas áreas com cobertura vegetal, em sub-bacias que têm maior potencial de geração de escoamentos intensos, em relação com as do sul, indicam uma forte tendência de aumento das intensidades e frequências das inundações, atingindo o aeroporto e a rodovia Presidente Dutra, além das perdas materiais e de vidas humanas das comunidades que ali vivem.

\subsection{Medidas corretivas}

Nos anos de 2001 e 2002, foi desenvolvido o Plano de Drenagem na bacia do rio Baquirivu-Guaçu pelo
DAEE, propondo 28 reservatórios (DAEE 2002), medida que inverte a lógica do aumento do escoamento das águas no canal mediante as canalizações tradicionais, passando a reter os volumes a montante. Entretanto, embora seja considerada uma tentativa de simular o mecanismo natural das várzeas, essas obras descaracterizam os serviços ecossistêmicos que a biosfera oferecia no quadro natural.

Dos 28 reservatórios propostos, está sendo anunciada pela prefeitura de Guarulhos a implantação de quatro a oito, além da canalização do canal do BaquirivuGuaçu.

De modo geral, os reservatórios apresentam menores custos em relação às tradicionais canalizações, sendo, até então, a opção mais coerente às bacias urbanizadas. No entanto, estudos realizados pelo Semasa (2001), em reservatórios em Santo André - SP, concluíram que os custos de manutenção são, em média, a cada três anos, um terço de seu custo total. Com sua construção, correse o risco de passar uma falsa sensação de segurança, estimulando a ocupação; e, ainda, sendo uma estrutura que requer manutenção permanente, sua gestão inadequada pode torná-la inoperante e, consequentemente, gerar uma inundação inesperada. Além disso, como se trata de reservação de águas com a presença de esgoto in natura, as condições de salubridade para as comunidades no entorno é algo a ser ponderado.

\subsection{Medidas preventivas}

Na perspectiva de expansão urbana na vertente direita, ao norte do rio, onde ainda subsistem vastas áreas com cobertura vegetal (figura 8), em sub-bacias com maior potencial de geração de escoamentos intensos que as do sul, indica-se forte tendência ao aumento das intensidades e frequências das inundações. Justifica-se e recomenda-se, portanto, a valorização dos serviços ambientais ou ecossistêmicos, promovidos pelas coberturas vegetais e florestas urbanas, gerando: atenuação das inundações e da regulação dos escoamentos hídricos das vertentes, redução das áreas de risco, regulação térmica, atenuação das ilhas de calor urbano e, ainda, os benefícios paisagísticos e culturais.

O Plano Diretor de Drenagem de Guarulhos, elaborado em 2008, estabelece diretrizes para a conservação de áreas vegetadas e várzeas, e o controle da expansão urbana ao norte. Entretanto, não há ainda nenhuma legislação com base em mapeamentos específicos, tampouco medidas efetivas ou propostas de disciplinamento do uso do solo que garantam tais diretrizes. 


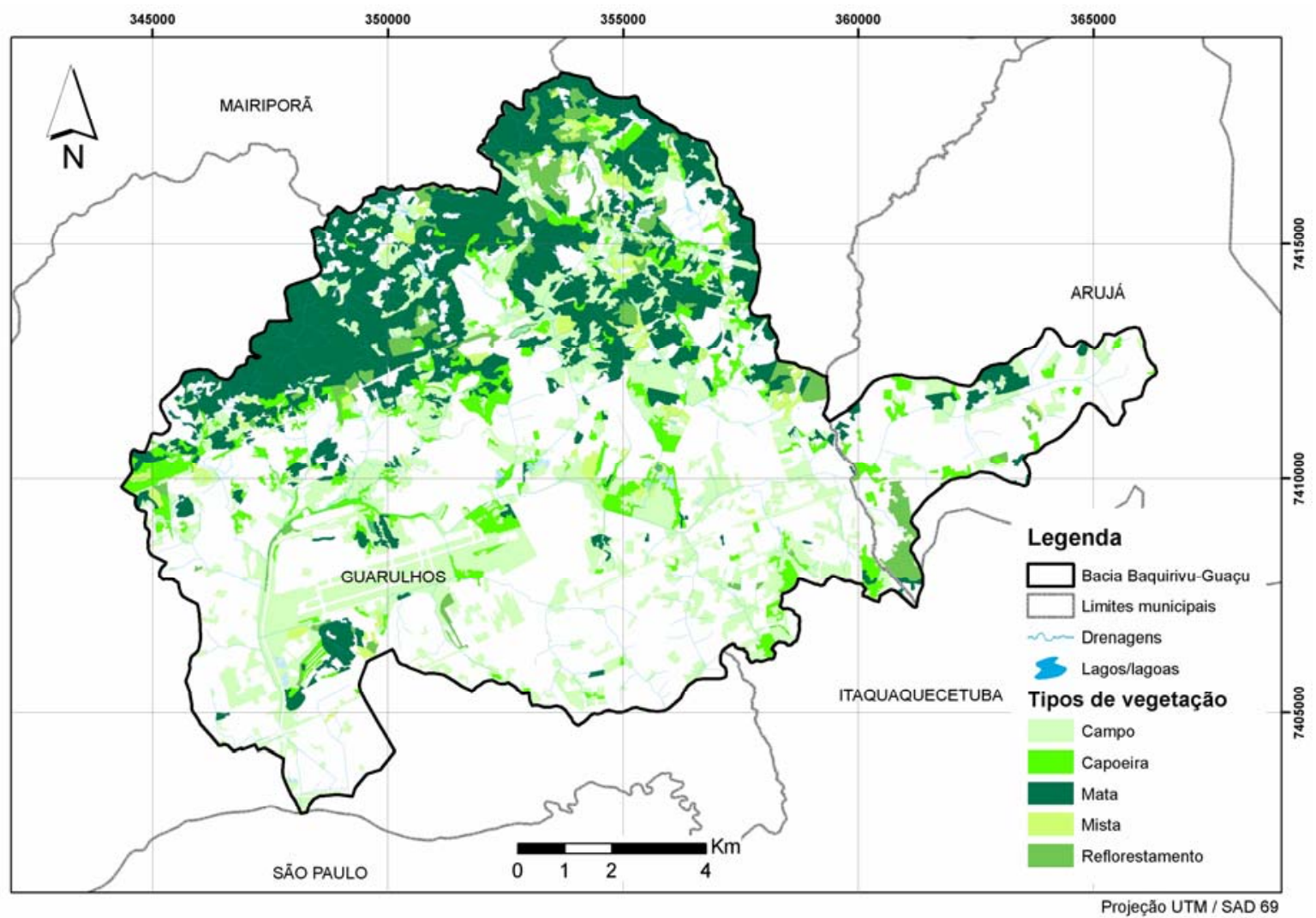

Figura 8: Evolução da área urbana na bacia do rio Baquirivu-Guaçu, segundo Campos (2011)

\section{Conclusões}

Considerando o modelo de ocupação que vem sendo seguido na bacia hidrográfica do Alto Tietê e sua reprodução na bacia do rio Baquirivu-Guaçu, é possível expor as conclusões a seguir apresentadas.

O quadro tecnogênico da bacia do rio BaquirivuGuaçu mostra que as inundações podem ser consideradas em dois espaços indissociáveis: o de sua extensa várzea e o das vertentes. Enquanto as vertentes vêm sendo impermeabilizadas e as várzeas descaracterizadas em suas funções naturais, as ocupações desses terrenos promovem danos devido às inundações que atingem o sistema viário estrutural, rodovia Presidente Dutra, o aeroporto e as comunidades.

Frente ao quadro tecnogênico de inundações, as medidas governamentais se limitam a uma sucessão de obras corretivas, que compreendem a implantação de reservatórios e canalizações, e de apropriação, a todo custo, dos espaços que ainda possuem função natural de amortecimento de cheias, persistindo o modelo de ocupação da BAT: falta de valorização dos serviços ecossistêmicos, como a atenuação das inundações pelas várzeas e a regulação dos escoamentos das vertentes pela vegetação, além dos demais serviços, importantes para o bem-estar humano, como os de regulação térmica, com atenuação da ilha de calor e, ainda, os benefícios paisagísticos e culturais.

O modelo, entretanto, permanece como determinante na reprodução urbana que reflete o modo de apropriação dos espaços; ou seja, a intervenção antrópica que altera o comportamento fluvial, ocasionando inundações, não mais naturais, mas como problema gerado tecnologicamente, cuja solução distorcida é a execução sequencial de obras cada vez mais onerosas ao poder público. Assim, é estabelecida a seguinte sequência: as inundações, ainda como fenômenos naturais, são consideradas como problemas a serem resolvidos, argumento que, em última instância, serve de subterfúgio para a ocupação das várzeas, destinando espaços para as atividades econômicas. Posteriormente, as inundações tornam-se realmente um problema, pois passam a atingir as ocupações equivocadamente permitidas, justificando a realização de novas obras, que oneram os cofres públicos continuamente.

Assim, contrapondo-se ao rito tradicional, este trabalho, ao criticar o modelo vigente, recomenda a aplicação de medidas preventivas, destinadas ao controle das inundações, num quadro tecnogênico que seja mais favorável ao bem-estar humano, preservando os serviços ecossistêmicos que restam na planície e na vertente norte da bacia do rio Baquirivu-Guaçu, ainda sem ocupação.

\section{Referências}

Alcamo J. et al. 2003. Ecosystems and human well-being: a framework for assessment: Millennium Ecosystem Assessment. EUA: World Resources Institute, 245p.

Campos D.C. de. 2011. Inundações: problemas ou fenômenos naturais? A ocupação das várzeas dos principais rios no Alto Tietê e a reprodução deste modelo urbano na Bacia do Rio Baquirivu Guaçu, Guarulhos, SP 2011. Dissertação (Mestrado) CEPPE - Centro de Pós-graduação e Pesquisa, Universidade Guarulhos, Guarulhos, 224p. 
DAEE - Departamento de Águas e Energia Elétrica. 1975. Projeto Básico de Canalização dos Rios Baquirivu-Guaçu e Guaió. Volume 2 - Ilustrações Rio Baquirivu-Guaçu. São Paulo: Secretaria dos Serviços e Obras - Engevix S/A, 42p.

DAEE - Departamento de Águas e Energia Elétrica. 2002. Plano Diretor de Macrodrenagem da Bacia Hidrográfica do Alto Tietê: Bacia do Baquirivu Guaçu - Diagnóstico geral e ações recomendadas. Relatório: PDATI-HI-RT-814. São Paulo: Secretaria Estadual de Saneamento e Energia, 84p.

EMPLASA - Empresa Paulista de Planejamento Metropolitano 2002. Região Metropolitana de São Paulo: Mapa do Uso e Ocupação do Solo da RMSP, escala 1:25000.

EMPLASA - Empresa Paulista de Planejamento Metropolitano. 1976. Plano Diretor de Drenagem da Bacia do Rio Baquirivu. Volume I - Relatório. São Paulo: Secretaria de Negócios Metropolitanos, 81p.

Guarulhos (Prefeitura Municipal). 2008. Plano Diretor de Drenagem de Guarulhos: Diretrizes orientações e Propostas. Guarulhos: Prefeitura Municipal de Guarulhos, 80p.

INFRAERO - Empresa Brasileira de Infraestrutura Aeroportuária. 1979. Fotos panorâmicas. Guarulhos: INFRAERO.

INFRAERO - Empresa Brasileira de Infraestrutura Aeroportuária. 2002. Estudo de Impacto Ambiental do Aeroporto Internacional de São Paulo/Guarulhos "André Franco Montoro". Brasil: Ministério da Defesa, 195p.

Jorge F.N. de; Uehara K. 1998. Águas de Superfície. In: Oliveira A.M. dos S., Brito S.N.A. de (org.). Geologia de Engenharia, São Paulo: ABGE, 101-109p.

Karmann I. 2000. Ciclo da Água, Água subterrânea e sua ação geológica. In: Teixeira W., Toledo M.C.M. de, Fairchild T.R., Taioli F. (org.). Decifrando a Terra. São Paulo: Companhia Editora Nacional, 113-138p.

Lacava M.A., Oliveira A.M.S., Pereira Filho A.J. 2009. Comportamento hídrico de superfície da bacia do rio Cabuçu de Cima, Parque Estadual da Cantareira, Guarulhos, SP. Revista Brasileira de Geomorfologia. 10(1):23-30.

Luís W. 2004. Na Capitania de São Vicente. Edições do Senado Federal - Vol. 24. Brasília: Senado Federal. 190p.

Mattes D. 2001. O Espaço das Águas: As Várzeas de Inundação da cidade de São Paulo. 2001. Dissertação (Mestrado) - Faculdade de Arquitetura e Urbanismo, Universidade de São Paulo, São Paulo, 200p.

Metrô News. 1984. Aeroporto trazendo progresso e valorizando extensa região. Metrô News. Guarulhos, 12 nov. [S.I.].

Oliveira A.M.S., Brannstrom C., Nolasco M.C., Peloggia A.U.G., Peixoto M.N. de O., Coltrinari L. 2005. Tecnógeno: registros da ação geológica do homem. In: Oliveira A.M.S., Souza P.E., Gouveia C.R. de, Suguio K. Quaternário do Brasil. Ribeirão Preto: Holos Editora, 363-378p.

Pereira Filho A. J., Santos P.M. dos, Xavier T. de M.B.S. (org.). 2007. Evolução do Tempo e do Clima na Região Metropolitana de São Paulo. São Paulo: Linear B; IAG/USP, 282p.

Riccomini C., Giannini P.C.F., Mancini F. 2000. Rios e Processos Aluviais. In: Teixeira W., Toledo M.C.M. de, Fairchild T.R., Taioli F. (org.). Decifrando a Terra. São Paulo: Companhia Editora Nacional, 191-214p.

Repórter de Guarulhos. 1977. Cumbica inundada; e não choveu. O Repórter de Guarulhos. Guarulhos, 02 de fev., ano I, n. 2, 4p.

Santos A.R. dos. 2002. Geologia de Engenharia: conceitos, métodos e prática.. São Paulo: Instituto de Pesquisas Tecnológicas - IPT: ABGE, 222p.

SEMASA - Saneamento Ambiental de Santo André. 2001. Estimativa de custos para manutenção do reservatório de detenção AM-03. Santo André: Prefeitura Municipal, 8p.

Tucci C.E.M. 2006. Gestão de águas pluviais urbanas. Brasil: Ministério das Cidades - Secretaria Nacional de Saneamento Ambiental. Programa Saneamento para Todos, 4 vol., 194p.

Vasp Aerofotogrametria S.A. 1971. Levantamento aerofotogramétrico de Guarulhos. Guarulhos: Prefeitura Municipal de Guarulhos,. 1 mapa, col. Escala 1:5000. 